\title{
Review
}

\section{Tolerance: A sensorial orientation to politics}

\author{
Lars Tønder \\ Oxford University Press, New York, 2013, xii+185pp., ISBN: 978-0-19-931580-2
}

Contemporary Political Theory (2016) 15, e1-e4. doi:10.1057/cpt.2015.8;

published online 24 February 2015

Lars Tønder's Tolerance offers a highly original and sharply presented analysis of one of the most important concepts in democratic theory. This book is very timely in terms of its pertinence to many of today's crises and catastrophes. Yet it is a perfectly untimely meditation insofar as it cultivates forgotten and disavowed theoretical insights that, on the one hand, disturb frames according to which tolerance appears merely as a punctual decision 'for' or 'against' something in light of pre-established reasons, and, on the other, move us toward a vision in which tolerance becomes an active practice for co-creating more relational, empowering and pluralizing futures. This is a book that exemplifies generosity in the way it reads others. Like Maurice Merleau-Ponty's discussion of exemplary art, it 'reaches its viewer and invites him to take up the gesture that created it' (Merleau-Ponty, quoted on p. 131). Below, I sketch this gesture and then raise some questions it invites.

Tolerance tenaciously pursues 'a main insight in the history of political thought: namely that politics entails an experience of becoming in which pain, broadly understood, is front and center' (pp. 134-135). Yet Tønder argues that many 'intellectualist' articulations of liberal democratic theory seek to banish painful becoming from the purportedly rational foundations and practices of political order. Chapter 1 powerfully criticizes this 'somatophobia' according to which reason is 'taken as universally accessible and as constituted in ways that are fundamentally different from the body and its sensorially inflected experiences'. Order and stability are privileged over disagreement and change, tolerance is secured and limited by an overlapping consensus based on reciprocity and universality, and intolerance is understood to be driven by passions that usurp our rationality (p. 28).

Tønder shows that this position is highly problematic. First, political liberalism disavows the complexity, plurality, contingency and affectively charged characteristics of the historical contexts in which it emerged. These disavowals deflect critical reflection, more modest horizontal engagements with other traditions and possible reformations. Second, insofar as it understands itself as purely rational, it is unable to perceive, critique and potentially transform relations toward otherness that involve 
questionable inflictions of suffering. Thus in painful conflicts liberalism tends to marshal dichotomous and often hysterical denunciations (for example, we, the rational and respectful, versus them, seething with disrespectful passions) that inflict further pain. Third, insofar as liberal tolerance is somatophobic, it engenders its own impossibility by undercutting the affective cultivation that is a condition for such politics. Fourth, by framing engagements with pain as politically disabling it contributes to the intractability of extant conflicts by blocking shifts from passive reactive tolerance toward an active and transfigurative tolerance. The latter 'may help us see how tolerance once again can become a progressive practice that aims to empower and pluralize the span of acceptable differences in society as well as generate the modes of subjectivity needed to support such orientation to contemporary politics' (p. 43).

Tønder develops a concept of 'active tolerance' in which our endurance of and resilience in relation to pain tends to engender unexpected co-creative connections. He 'pluralizes pain's many meanings in order to engage the diverse worlds, experiential registers and agentive capacities that the encounter with something painful might invoke' (p. 43). Chapter 2 engages several modern theorists in order to disclose alternative understandings of pain and political possibility that greatly complicate reductionist histories in which everything points toward and vindicates contemporary liberalism. Provocatively off-beat readings of Descartes, Locke, Kant, Mill and Nietzsche initiate a counter-memory that considers ways in which pain has duration susceptible to intervention, is the result of complex nonlinear relationships among several registers of being (for example, cognitive, perceptual, affective), is integral to enlivenment and is indispensable for thinking and developing connections and power with others and the world. This immanently illuminates the contingency and contestability of much contemporary democratic theory, and challenges critical theorists who would break from tolerance because they view it as essentially repressive.

Chapter 3 deepens these insights through a reading of "the "tragic moments" of Spinoza's philosophy of immanence', which draws out their affirmative and expansive character for a politics of democratic empowerment and pluralization (p. 80). Inspired by Spinoza, Tønder suggests a 'force field of tolerance' that implies 'a dynamic process of becoming wherein affects and other sensorially inflected powers sustain the endurance of some experiences of pain but not others, and where tolerance's plurality and politicality is directly linked to the possibility that tolerators might differ from one another ...' (p. 82). He cultivates 'gravity points' in this force field by interweaving theoretical frames, affects, perceptions, desires and practices that conspire to orient and mobilize us toward a powerfully transformative politics. Spinoza theorizes painful passions in ways that disclose how we are overtaken by unexpected otherness that presents us with disagreeable obstacles, yet energizes new imagination, connections, movements and counterpowers - potentia. Painful passion 'cuts through the fabric of Being as it traces the decay and rebirth of embodied life, 
empowering new constellations of thought and action while also subverting the autonomous self-government that persons and collectives desire in the interest of self-preservation' (pp. 93-94). Tønder eloquently summarizes his cross-grained reading of Spinoza: 'We find a subsisting pain that finite beings must tolerate if they want to live and engage with each other. Their coexistence ... makes them vulnerable in love, hope, and titillation' (p. 94).

These ideas, along with Chapter 4's compelling readings of Merleau-Ponty's phenomenological 'tolerance of the incomplete' and his 'synaesthestic understanding of how different senses immanently check and inform one another in unending, dynamic and shifting efforts to make sense of things', culminate in Tønder's theory of 'sensorial reasoning'. Rather than only seeking critical distance from the contingencies of context and bodily experience, 'in addition and more importantly, reason also stands forth as a sensorially inflected way to examine these contingencies' (p. 127). Tønder's wager is that a politics that resiliently engages the messy and often disagreeable work of co-creating transformative connections will foster virtuous circles in which ontology, ethics, desire, action and empowerment intensify and modulate to better respond to seemingly intractable conflicts.

Throughout the book, Tønder moves between theory and insightful analyses of contemporary political practices and conflicts, ranging from the 'Danish cartoon war', to Dave Chappelle's comedic engagements around race, to the Freedom Riders, to masochism, to questions of torture. His engagements with these issues often disclose the power of his theoretical work, as for example when he simultaneously pluralizes liberalism, Islam and the twelve Danish cartoons to conjure up a political engagement far more hopeful than what actually transpired; or when he reads Chappelle's skits in light of the incongruous and energizing combinations of pleasure and pain that Spinoza calls hilaritas, in order to engender empowering relationships across racial differences.

Yet just as Tønder understands pain as 'an obstacle to unhindered movement and effortless creation - a sense of being limited, stopped in one's tracks, for reasons that seem more or less than just' (p. 9), I found myself wanting the text to dwell with its own pain a bit more directly - the places, times and ways in which active tolerance might face its own limits and even require them as immanent agonistic conditions of its own possibility. The political stakes are significant. Tønder takes us an impressive distance toward an empowering and pluralizing politics that responds to Herbert Marcuse's critique of 'repressive tolerance' and his call for 'a partisan goal, a subversive liberating notion and practice' (Marcuse, quoted on p. 79). Yet we might emphasize a painful sentence from the Marcuse passage that Tønder quotes but does not endure: 'The conclusion ... is that the realization of the objective of tolerance would call for intolerance toward prevailing policies, attitudes, opinions, and the extension of tolerance to policies, attitudes, and opinions which are outlawed or suppressed' (p. 79). I think the question of how certain practices of intolerance may be conditions for active tolerance haunts but is not quite addressed in this text. 
As noted, active tolerance involves 'the endurance of some experiences of pain but not others' (my emphasis).

The Freedom Riders appear too briefly in this text, but they nevertheless raise questions that exceed the 'practice of pluralization' theme within which they are largely framed (p. 86). To say in this context that their 'endurance of pain is mobilized not to dominate or repress but to affirm a presumptive generosity toward others' (p. 87) both evokes some of the highest ethical sensibilities and political practices of many who rode into Jim Crow hell, and avoids the extent to which most sought precisely to repress the institutions, practices, relationships, ideologies and sensibilities that sustained this hell. They understood their capacities to live lives of active tolerance to be immanently connected with this intolerant limit - struggles for political hindrance, blocking, destruction - every bit has much as they were borne by a politics with affinities to those Tønder pursues. I suspect that in an age of New Jim Crow, climate catastrophe, obscene capitalism and malignant xenophobia, questions concerning the arts of negotiating these difficult tensions will continue to be central to struggles for a better world.

To raise these difficulties is not to affirm the need for public reason as a rational ground of active tolerance. Nor is it a call to embrace Marcuse's own political articulations. Rather it is to acknowledge a pressing and in some sense more complicated set of questions that Tolerance repeatedly broaches but does not quite endure. Still, Tønder's penetrating account offers indispensable tools for discerning, negotiating, experimenting and struggling with these always-evolving relationships between modes of tolerance and modes of intolerance, and this reviewer very much looks forward to his next book.

Romand Coles

Northern Arizona University, Flagstaff, AZ 86001, USA 